\title{
Quantitative Literacy in the Affective Domain: Computational Geology Students' Reactions to Devlin's The Math Instinct
}

Victor J. Ricchezza

University of South Florida, vricchezza@gsu.edu

H. L. Vacher

University of South Florida, vacher@usf.edu

Follow this and additional works at: https://digitalcommons.usf.edu/numeracy

Part of the Geology Commons, and the Other Mathematics Commons

\section{Recommended Citation}

Ricchezza, Victor J., and H. L. Vacher. "Quantitative Literacy in the Affective Domain: Computational Geology Students' Reactions to Devlin's The Math Instinct." Numeracy 10, Iss. 2 (2017): Article 11. DOI: http://doi.org/10.5038/1936-4660.10.2.11 


\title{
Quantitative Literacy in the Affective Domain: Computational Geology Students' Reactions to Devlin's The Math Instinct
}

\begin{abstract}
Building on suggestions from alumni from a recent interview project, students in Computational Geology at the University of South Florida were tasked with reading a popular non-fiction book on mathematics and writing about the book and their feelings about math. The book, The Math Instinct by Keith Devlin, was chosen because we believed it would give the students something interesting to write about and not because we had any expectations in particular about what it might reveal about or do for their math anxiety. The nature of the responses received from the students led to the performance of a post-hoc study on the emotional affect of math in the students' lives and how it changed as they proceeded through the book and reflected back on it at the end. Of the 28 students in the fall 2016 section of the course, 25 had an improved or slightly improved attitude toward math by the end of the semester. The assignment was more successful than we could anticipate at generating thought and getting students to communicate about math - an integral component of quantitative literacy. Although the limited size and post hoc nature of the study make it difficult to generalize, the results are promising and invite further use of the assignment in the course.
\end{abstract}

\section{Keywords}

Affective Domain, Math Anxiety, Qualitative Research, Math Education, Geoscience Education, Student Writing

\section{Creative Commons License}

\section{cc) (7) (8)}

This work is licensed under a Creative Commons Attribution-Noncommercial 4.0 License

\section{Cover Page Footnote}

Vic Ricchezza and Len Vacher are a doctoral student/teaching assistant and professor, respectively, in the Geology program in the School of Geosciences at the University of South Florida, Tampa. 


\section{Introduction}

In this note, we detail and discuss our observations from a post hoc study conducted in our quantitative-reasoning-in-geology course. This study reviewed student submissions from a reading/writing assignment that was given as a sidelight to the students' work on geological-mathematical word problems. We asked whether students' disposition toward math changed after reading The Math Instinct (Devlin 2005).

\section{Quantitative Literacy in the Affective Domain}

The meaning of "quantitative literacy" (QL), "quantitative reasoning" (QR), and "numeracy" is a recurring topic in Numeracy (e.g., Vacher 2014; Karaali et al. 2016). Despite any disagreement on the finer distinctions between these terms, however, some basic connotations and uses seem near-universal. One such commonality is exemplified by Madison (2006, p. 2323): "QL is a habit of mind rather than a content-rich academic discipline." But how can a "habit of mind" be studied, discussed, and taught? Surely, attitude and affect come into play. To clarify in this context what we mean by affect, we are referring to the affective domain (Krathwohl et al. 1964) of educational psychology as the branch dealing with emotions and feelings (as opposed to behaviors or thoughts). ${ }^{1}$

We have noted an apparent trend when reading articles on QL instruction: the articles concentrate mostly on the cognitive domain, while expending less effort on any emotional component. But our students are not unemotional automatons. Quite to the contrary, over the 20-plus years that the Computational Geology (CG) course has been offered at the University of South Florida (USF) (Vacher 2000; Ricchezza and Vacher 2017), it has become quite obvious that many (if not most) of our students have an emotional, at times visceral, response to mathematics.

Our experience is by no means unusual. As noted by (Hart 1989, p. 38), for example,

It is relatively clear that decisions about how many and which mathematics courses to take in middle school, high school, and college can be influenced by affective characteristics of the student that have developed over many years.

This view is supported by studies indicating that a student's experiences with mathematics in $7^{\text {th }}-10^{\text {th }}$ grade classes influenced how they performed in mathematics in the $12^{\text {th }}$ grade, which in turn influenced whether they chose to be a science, technology, engineering, or mathematics major in college (e.g.,Wang 2013). The choice, in fact, may be due to how mathematics is taught and used in the United States (e.g., Follette et al. 2017).

\footnotetext{
${ }^{1}$ http://open.lib.umn.edu/socialpsychology/chapter/1-2-affect-behavior-and-cognition/
} 
Student emotions regarding mathematics noted in prior interviews with CG alumni reported in Ricchezza (2016) range across a wide variety of attitudes about math education, math practice, and even basic situations where mathematics make unexpected appearances. These attitudes (among CG students) vary from the most positive and enthusiastic to extremely negative and math avoidant. Indeed, while our paper focuses now on the breadth of feelings and emotions evoked by a new, semester-long writing assignment in CG, our attention at the time of implementing the assignment was not focused specifically on math anxiety or math avoidance but rather on improving the students' communication skills when discussing mathematics. However, once we read the responses, math anxiety and math avoidance - i.e., math in the affective domain - came to the fore.

The phenomenon of math anxiety should come as nothing new to the readers of this journal. Math anxiety can be described as "a feeling of tension, apprehension, or fear that interferes with math performance" (Ashcraft 2002, 181); it is only weakly related to overall intelligence, but leads to an avoidance of math activities by those afflicted with it. Thus the math-anxious predictably achieve less in math relative to those who do not suffer from math anxiety (Ashcraft 2002).

Indeed, more specifically regarding numeracy, math-anxious individuals perform poorly relative to their own apparent thinking and reasoning ability in nonnumerical tasks (Maloney and Beilock 2012). Maloney and Beilock go on to state that this anxiety may develop early in education - as early as elementary school. A pattern of brain activity is associated with negative emotions and numerical computations in those affected, and teachers can pass along negative attitudes to their students. However, "when anxiety is regulated or reframed, students often see a marked increase in their math performance" (Maloney and Beilock 2012, 405). Some articles published by this journal demonstrate this ability to mitigate math anxiety through modest teaching innovations (Wismath and Worrell 2015; Lipka and Hess 2016; Follett et al. 2017). Of course, not all such interventions produced the desired results (Sundre et al. 2012; Mayfield and Dunham 2015).

In "Twenty Questions about Mathematical Reasoning," Steen (1999a, Question 10) asks "Does 'math anxiety' prevent mathematical reasoning?" Steen gives the short answer, "yes... sort of" - what students fear is not mathematics so much as how it is presented in schools. Indeed, in "Reading, Writing, and Numeracy," Steen (2000) lists one of the goals of numeracy or QL as "reduced anxiety: diminishing the negative effects of school-grown "math anxiety."”

A quick literature review found three Numeracy articles relating specifically to math anxiety and math avoidance. A QR course at Seattle University (Henrich and Lee 2011) used "service learning" (making students into tutors, essentially) and studied the effect on student attitudes toward math and math anxiety; results indicated clear improvements. A survey (Wismath and Worrall 2015) of a Canadian university QR course (discussed earlier in Wismath and Mackay 2012) found strong 
improvements in self-reported student attitudes toward their own math abilities and toward perceived math anxiety. A study on math anxiety at Portland State University (Latiolais and Laurence 2009), expanded to math avoidance, led to two different course-type offerings specifically to help math-avoidant students find help. Other examples can be found over a wide range of other journals, such as Childhood Education (Furner and Berman 2003), Journal of Research in Mathematics Education (Ho et al. 2000), and Journal of Counseling Psychology (Betz 1978).

\section{Course Background}

Computational Geology (CG) is a QL-in-geology course at the University of South Florida (USF) ${ }^{2}$ and has been a fixture in the geology (GLY) major there since its initial offering in 1996 (Vacher 2000; Ricchezza and Vacher 2017). The CG course came about because many students - most notably from the ranks of the so-called nontraditional students, i.e., students who were restarting their education after various life experiences - realized that they did not possess the mathematical skills they would need to obtain and perform the jobs they sought (Vacher 2000). The second author (LV) created the course and was its sole instructor during 1996-2015, and he has taught it in alternation with another professor since 2016, when the course went from a once-per-year offering to twice-per-year. The primary author (VR) has been the graduate teaching assistant (TA) for the course since the fall 2015 semester and completed a qualitative study of the course featuring interviews with alumni spanning the course's history (Ricchezza 2016).

The course has undergone significant changes in instructional methods and content over its two decades (Ricchezza and Vacher 2017). From the beginning, CG has consistently been heavy on using spreadsheets to teach geologicalmathematical problem solving (Vacher 2000; Vacher and Lardner 2010) and is now near obsessively focused on geology-context word problems. In the early years, the course was seen as a capstone to the GLY department's requirement of a year of calculus. It soon evolved to what LV considered a QL course emphasizing material that the geology students had missed - for a variety of reasons - in their mad path to calculus (i.e., GATC). Operationally for the course, he came to think of QL in terms illustrated by the course-contemporary slide shown in Figure 1. Note, according to this portrayal, QL is antipodal to math phobia, anxiety, and avoidance.

${ }^{2}$ USF is a multi-campus public university, with the main campus (42,000 students) set amidst the northern urban sprawl of Tampa, Florida (http://www.usf.edu/about-usf/facts.aspx). The Carnegie Foundation for the Advancement of Teaching classifies USF as both a Doctoral University with "Highest Research Activity"(RU/VH) and a "Community Engaged" institution (http://news.usf.edu/article/templates/?a=3070). USF is home to many non-traditional students, including returning military veterans, two-year college transfers, and students returning to school after long absences. The CG course aims to prepare geology majors for more-advanced geology courses involving math and for success in the workforce. 
Not surprisingly, the subject of math anxiety was brought up by some of the alumni interviewed by Ricchezza (2016).

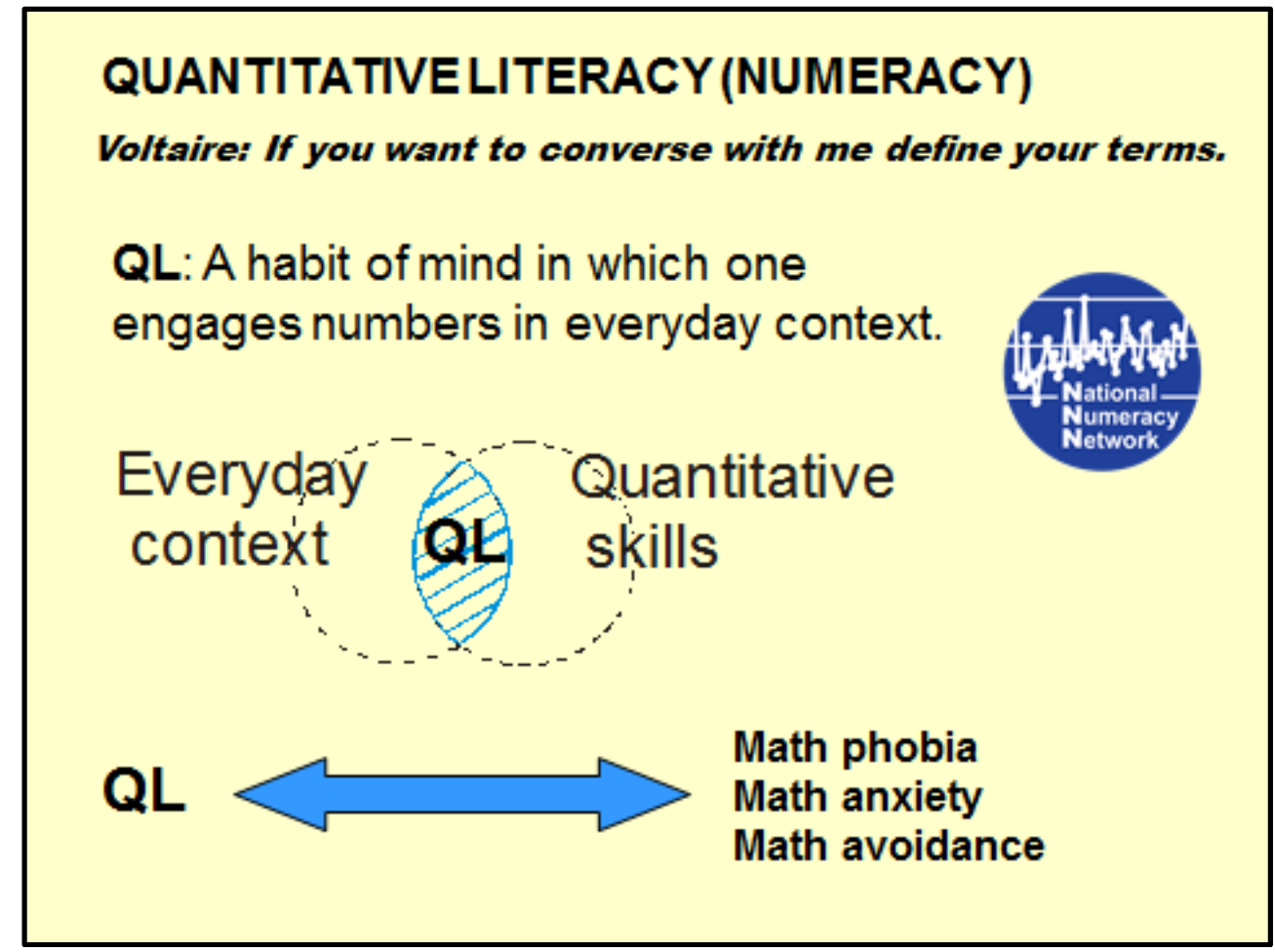

Figure 1. Definition of Quantitative Literacy. Slide defining QL for a presentation on the role of geoscience education in promoting QL (Vacher 2006) at a workshop of the National Association of Geoscience Teachers.

The interviewed alumni were also asked about what they thought today's students should be learning now that would help them succeed professionally after graduation. Several stated that written communication skills were vital, and they noted that such skills were lacking in many of their recent hires (Ricchezza 2016). Remembering that effective communication of arguments using quantitative evidence is a primary component of QL (Steen 1999b), and that a course designed for QL and/or QR "requiring students to write responses promotes clearer thinking" (Madison 2014), we added a writing assignment to the course for the fall 2016 cohort. The addition of this writing assignment was in response to the alumni suggestions from prior studies and was for course improvement. No thought was given beforehand to our writing a paper on the experience. After the data were collected, however, it became apparent that what we had collected was of such interest that we would be wasting a valuable opportunity if we did not perform a post hoc study based on the collected data. 


\section{Methods and Approach}

All 28 students in the fall 2016 CG course section were given, as a normal component of their coursework, a reading/writing assignment that constituted $10 \%$ of their final course grade. Students were also assigned to write a series of word problems for another $10 \%$, but the word problem assignment was not new for the fall 2016 semester and was not considered for this study. Writing submissions were graded for completion (all grading of writing assignments was done by LV); feedback was largely concentrated on encouraging the students to push through difficulties, with occasional commentary on major lapses in grammar, spelling, or attention to detail. Writing submissions were handed in through the online coursemanagement software provided by USF, with text entry for all items except the final assignment, which required students to upload a one- to two-page document for plagiarism checking.

Students were asked during the first week of class to give "a two-paragraph statement describing what [they] think of [their] experience with mathematics and [their] attitude toward the subject." Students were then required to read The Math Instinct: Why You're a Math Genius (along with Lobsters, Birds, Cats, and Dogs) (Devlin 2005). At the conclusion of each week (starting week 2), students responded to a chapter of Devlin's book until the $13^{\text {th }} /$ final chapter was finished in week 14. Students then submitted a final assignment - a one- to two-page statement in response to the following prompt:

...[D]escrib[e] what you got out of the book. Recall what you wrote in the first assignment, which was "a two-paragraph statement describing what you think of your experience with mathematics and your attitude toward the subject." Has anything changed in that regard as a result of your experience with that book?

After submission of the final assignment and completion of grading, student submissions were de-identified by copying the text entries (without identifying information) into a spreadsheet. Each student name was replaced by a unique random number between one and twenty-eight using dice, and each student's entire submission catalog was then copied into the spreadsheet under the appropriate column. (Thus, "Jane Smith" might become "Student 12"). This labelling allowed us to keep track of changes to student attitudes longitudinally within the semester without noting or publishing any identifying student information.

Prior to copying of student submissions from the online course-management system, details of the proposed study were submitted to the USF Institutional Review Board (IRB) for approval. Because the semester had concluded, the IRB approved a waiver of informed consent, provided that the students' information was removed. The project was granted IRB approval e29371. 


\section{Analysis}

\section{Research Question.}

Stipulated that this study was post hoc, the following research question drove the analysis of the existing data:

- How did students' self-reported attitudes about math change after being assigned to read and respond to The Math Instinct (Devlin 2005)?

\section{Coding.}

Data were copied from the master spreadsheet to a word processing document, and responses were studied for common phrases and words (codes). Coding was performed using grounded theory - that is, codes were determined based on what appeared in the data, not predetermined codes (Glaser and Strauss 1967). All coding was done by VR. Four general codes were identified in the reading:

- Positive attitudes about mathematics.

- Negative attitudes about mathematics or math classes.

- Interest, fascination, or "liked reading" something from the assigned book.

- Thinking which began or changed due to something the student encountered in the book.

\section{Results}

\section{Summary of the Assigned Book}

The Math Instinct (Devlin 2005) makes the following statement on the back cover:

There are two kinds of math: the hard kind and the easy kind. The easy kind, practiced by ants, shrimp, Welsh corgis - and us - comes naturally. The hard kind... well, it doesn't come naturally to many of us.

In The Math Instinct, Keith Devlin argues that, if we want to do better in formal math, we should see how it arises from natural mathematics - and he shows us how to get the most out of the skills we already have.

Chapters 1 through 8 concentrate on examples of what Devlin refers to as natural mathematics - that is, activities that require an understanding of patterns that can be expressed mathematically - such as a dog determining (correctly and repeatedly) the most efficient path to run and swim to chase a ball thrown into the ocean at an angle. Chapters 9 through 12 transition to a discussion of abstract mathematics - the sort of thing one generally learns in a mathematics classroom in school. Chapter 13 ends the book by discussing the way math is taught in school and giving some tips on how to optimize learning within that system. Table 1 includes a statement on each chapter from 13 selected students. 
Table 1.

Selected Student Chapter Summaries

\begin{tabular}{ll}
\hline Chapter & Quotation \\
\hline $\mathbf{1}$ & From reading chapter 1 of "The Math Instinct," I learned that numerosity is sense of numbers, the most \\
basic instinct developed at a very young age. I was surprised to learn that infants as young as 4 days \\
old can recognize the difference between having more or less of something when it comes to small \\
numbers $(0,1,2,3)$. - Student $\mathbf{1 5}$ \\
Chapter 2 was interesting to me because he broke down calculus, and math in general, into its most \\
fundamental parts. He said that Elvis, the welsh corgi, was performing calculus on the ball every time \\
he ran along the beach and then into the water to retrieve the ball calculating the shortest possible \\
distance. This made me think about our everyday lives and how we as humans are constantly \\
calculating things without even realizing it, like driving a car and knowing when to pass a car driving \\
the same speed as you, so you adjust your speed accordingly. - Student 17 \\
This chapter has been the most interesting to me so far. The way this chapter explained what math is, is \\
a way I knew existed but had never really had explained to me or had been one I had thought much \\
about. I like the distinction one can make between "math" as it is normally thought of and "Natural \\
Math." In my opinion, if kids were taught math as a way of pattern recognition and rules of logic as \\
opposed to rearranging of numbers, more people would have a better view and understanding of it. - \\
Student 11
\end{tabular}

4

I am just as interested in the Tunisian ant finding the fastest way home as I am in the lobster's Magneto like powers. The ant's ability to successfully navigate back to a hole a millimeter big is one amazing internal compass. Direction is one thing, but to know the exact distance is mind blowing. I knew something about lobsters migrating to the same area to reproduce but never thought about how they find their way. Sensing Earth's magnetic field would have never even been a thought. - Student 9

The honeybees innate ability to build perfect regular hexagons was astounding to me. Honeybees accuracy in making sure that all the widths are exactly the same and they all meet at 120 degrees far surpasses my ability, even if I had all sorts of tools available to use. Although the spider wasn't intentionally building a beautiful geometric shape, the end result is still impressive. This chapter left me wondering why we haven't evolved to be able to do mathematics to this degree with instinct. Student 16

6 What I found most interesting is that leaves wind around the stem of a plant according to the Fibonacci sequence. I already knew that many types of flowers have a Fibonacci number as their number of petals from a documentary I had watched, but I didn't know that trees followed the sequence as well with their leaves. It's incredible that the leaves on a stem grow so as to maximize the amount of sunlight they receive but also make sure to not block or be blocked by other leaves. There is no way I'm going to be able to walk past a tree anymore without stopping to examine a branch to see if the leaves have a divergence that includes Fibonacci numbers. - Student 19

7 Reading through this chapter really made me think about what all goes into the aspect of motion of the everyday things we have around us. One example in the book that stood out to me the most was when the author was comparing how fish propel themselves by pushing the water sideways with their tale; birds fly by flapping their wings to create lift and forward thrusts. Both of these creatures are completely different, but manage to find a way to make motion work in their favor. Looking at how there are many different ways that represent different views of motion, gets your mind thinking when you realize all it comes down to is two physical principles which are mass and acceleration. - Student 4

8 What I found most interesting in chapter 8 was the two ways that the brain uses to determine depth. The first way being the measurement between the angle of the two eyes as they focus on a distant object. The second way being how much the eye distorts in order to bring an image into focus. It's amazing how such a complex process is done nearly instantaneously in the brain without conscious thought. - Student 10

9 Devlin wraps up his exploration of animals performing mathematical feats in Chapter 9 with his classification of which animals actually perform math and which ones use their adaptations from natural selection. The difference between both categories is the manipulation of numbers and concepts via mental processes. While a lot of animals cannot perform mental math in the traditional sense, some can be trained to do mathematical concepts. The animals that are able to do this are: rats (although I found the training to be inhumane and saw their learning as one based on fear rather than curiosity), birds (with their number sense), lions (also number sense), and chimpanzees (with the ability to perform simple arithmetic). On a related side note, I found the Hans the Horse story to be incredibly humorous as the poor trainer wanted his horse to do math and the horse simply followed his trainer's cues with no mental thoughts whatsoever. - Student 24 


\begin{tabular}{|c|c|}
\hline Chapter & Quotation \\
\hline 10 & $\begin{array}{l}\text { Reading about "street mathematicians" in South America and how they use transformation rules to } \\
\text { quickly solve their problems is another reason how practice and motivation is the only way to improve } \\
\text { math skills. These children depend on math and therefor are highly motivated to get to the right } \\
\text { answers as Keith Devlin explained. To something most students relate to these days is that math } \\
\text { classes teach people how to perform on tests but they do not teach how to solve real life problems. } \\
\text { This is problematic because if you're away from these methods for a period of time you not only forget } \\
\text { how to do the problems on a test but you also end up having to teach yourself how to solve real life } \\
\text { problems, as was the case for shoppers. If real life math skills such as the transformation rules were } \\
\text { taught at a younger age in math classes, I think all of us would see more success in basic math on both } \\
\text { tests and real world situations. I'm always surprised how quickly my father always beats me to the } \\
\text { answers of arithmetic problems and now I'm curious whether that is something they taught him in } \\
\text { school in (...) or just through real world experience. - Student } 6\end{array}$ \\
\hline 11 & $\begin{array}{l}\text { This chapter is about counting and its various forms and meaning to people. The author spends a good } \\
\text { portion of the chapter just discussing how humans are born with an innate ability to differentiate up to } \\
\text { the number three. He also covers how counting has played a part of civilization in various forms from } \\
\text { India to Arabic countries. It is heavily argued that counting has a different meaning to each person and } \\
\text { in each case, can determine their ability to count. Some people numbers mean a great many things and } \\
\text { are gifted counters while others are comfortable in the basic regard of counting. The chapter ties it } \\
\text { together by stating that mathematics is a fantastic form containing many meanings but to each person, } \\
\text { this meaning can define how they choose to see math, some will love wholeheartedly and other not so } \\
\text { much. - Student } 7\end{array}$ \\
\hline 12 & $\begin{array}{l}\text { Chapter } 12 \text { was quite interesting. This chapter helped me to understand why I tend to struggle with } \\
\text { math and why I tend to forget things right after a test. I enjoyed reading about how people struggle } \\
\text { with seemingly meaningless sequences of operations on insignificant symbols, and then as a result they } \\
\text { end up with very odd-ball answers. I do this a lot, if I don't understand something I will make up my } \\
\text { own equations or set of rules for a problem. And then as stated in this chapter once the correct answer } \\
\text { is explained to me, it makes total sense. In addition, I really find it interesting that people are better } \\
\text { able to do math if it pertains to real life. I never even thought of that. My favorite part about this } \\
\text { chapter was when the author talked about school arithmetic and how people never get to the meaning } \\
\text { stage; and it just remains forever an abstract game of formal symbols. I feel like this is truest statement } \\
\text { about math. - Student } 26\end{array}$ \\
\hline 13 & $\begin{array}{l}\text { This chapter is about how natural mathematics is a product of the mechanism of evolution. That we } \\
\text { have been using the same innate mathematical processes since the Iron age. That the development of } \\
\text { "abstract mathematics" is still a very new thing and is still very unfamiliar to many. The chapter also } \\
\text { covered ways to improve one's mental math skills. - Student } 21\end{array}$ \\
\hline
\end{tabular}

\section{Counts and Percentages}

The writings of all 28 students were reviewed for this study. Three had a clear positive attitude about math at the beginning; two had a mostly positive attitude; four had a negative attitude, and the remaining 19 had a mixed positive/negative attitude at the start. Student 21 did not complete the first (initial-attitude) assignment; however, this student self-evaluated the initial attitude at the start of the final assignment and was counted as "mixed," which appeared consistent with the student's statements on chapter readings.

There were 15 separate assignments (the introduction, 13 chapter responses, and the final statement) for each of 28 students; therefore, there were 420 total assignments. The non-response rate was 13\% (Fig. 2a). There were 13 chapters in the book, and 28 students reading the book; therefore, there were 364 chapterresponse assignments. Out of that total, $51 \%$ of the individual chapter responses were coded as being "interesting" or "fascinating" in the students' own words (Fig. 2b), and $26 \%$ were coded as including an explicit statement that the chapter 
provoked a new or changed line of thought (Fig. 2c). It should be noted that this last code was also seen in a majority of the final assignment responses.

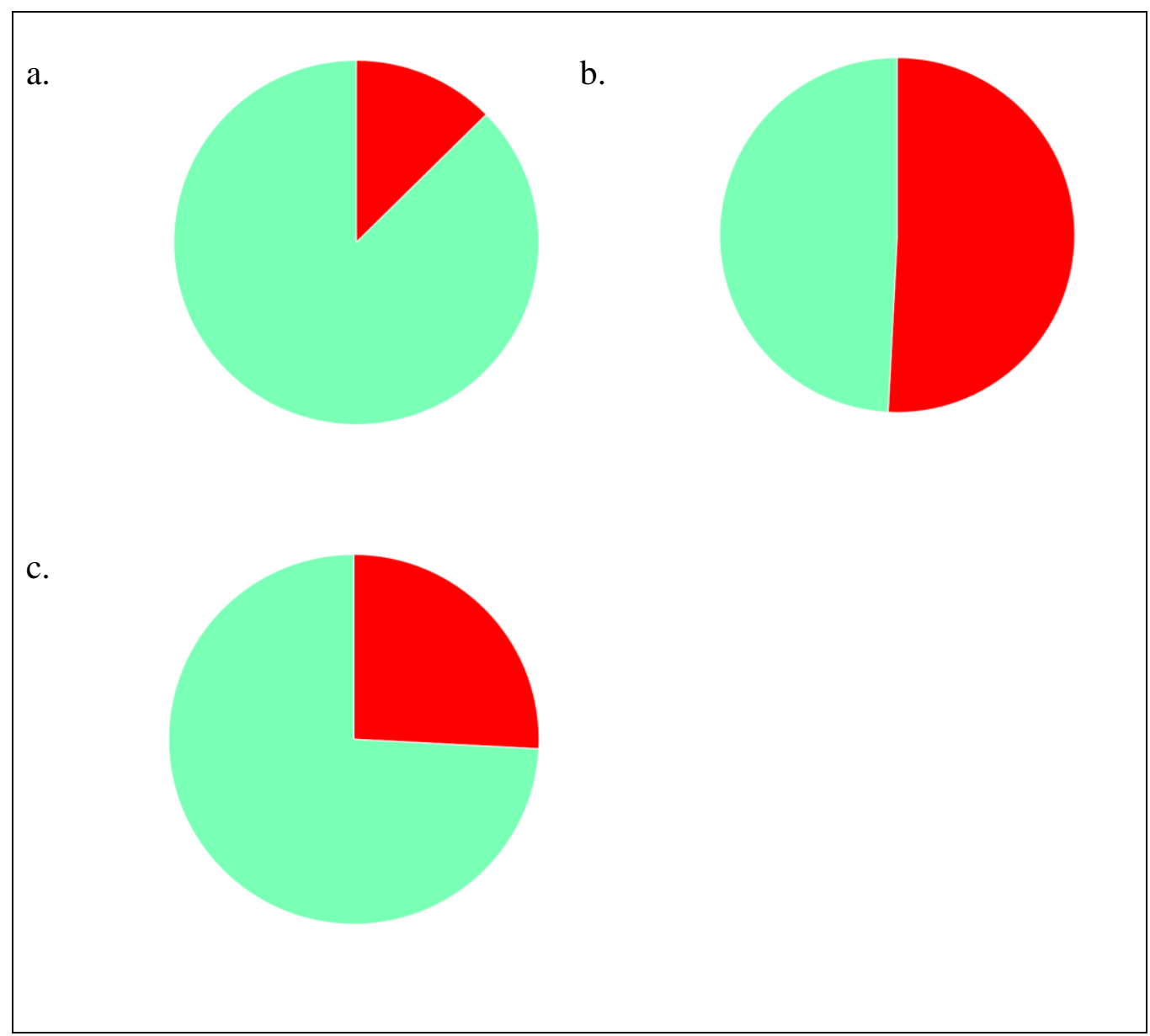

Figure 2. Results.

(a) Proportion of assignments turned in (green) (367/420);

(b) Proportion of chapter-response assignments that were said to be "interesting" or "fascinating" in the students' own words (red) (185/364);

(c) Proportion of chapter-response assignments that included a statement that the reading provoked a new or changed line of thought (red) (94/364).

Student attitudes were assessed at the start and end of the reading and writing assignment. Attitude changes were examined and classed into three groups: improvement, minor improvement, and unchanged. (See Table 2.) No students exhibited any signs that their attitude toward math became more negative after reading the book, although not all students enjoyed the book itself. For the groups identified in the starting assignment: 
- 3 Positive attitudes at start

○ 2 Improvement

○ 1 Minor Improvement

- 2 Mostly Positive attitude at start

○ 1 Minor Improvement

$\circ 1$ Unchanged

- 19 Mixed attitude at start

○ 11 Improvement

- 6 Minor Improvement

$\circ 2$ Unchanged

- 4 Negative attitude at start

○ 4 Improvement

Table 2.

Student Starting Attitudes and Changes

\begin{tabular}{ccc}
\hline Student & Attitude at start & Attitude at end \\
\hline $\mathbf{1}$ & Mixed & Minor improvement \\
$\mathbf{2}$ & Mixed & Improvement \\
$\mathbf{3}$ & Mixed & Improvement \\
$\mathbf{4}$ & Positive & Improvement \\
$\mathbf{5}$ & Positive & Improvement \\
$\mathbf{6}$ & Mixed & Improvement \\
$\mathbf{7}$ & Mixed & Improvement \\
$\mathbf{8}$ & Positive & Minor Improvement \\
$\mathbf{9}$ & Mostly positive & Unchanged \\
$\mathbf{1 0}$ & Mixed & Minor Improvement \\
$\mathbf{1 1}$ & Mixed & Unchanged \\
$\mathbf{1 2}$ & Mixed & Minor Improvement \\
$\mathbf{1 3}$ & Mixed & Minor Improvement \\
$\mathbf{1 4}$ & Negative & Improvement \\
$\mathbf{1 5}$ & Negative & Improvement \\
$\mathbf{1 6}$ & Negative & Improvement \\
$\mathbf{1 7}$ & Mixed & Improvement \\
$\mathbf{1 8}$ & Mixed & Minor Improvement \\
$\mathbf{1 9}$ & Mostly positive & Improvement \\
$\mathbf{2 0}$ & Mixed & Improvement \\
$\mathbf{2 1}$ & Mixed & Unchanged \\
$\mathbf{2 2}$ & Negative & Improvement \\
$\mathbf{2 3}$ & Mixed & Improvement \\
$\mathbf{2 4}$ & Mixed & Minor improvement \\
$\mathbf{2 5}$ & Mixed & Improvement \\
$\mathbf{2 6}$ & Mixed & Improvement \\
$\mathbf{2 7}$ & Mixed & Improvement \\
$\mathbf{2 8}$ & Mixed & Improvement \\
\hline $\mathbf{1 2}$ & & \\
\hline
\end{tabular}

\section{What the Students Said}

Table 3 includes a selection of some student responses to give a flavor of the students' reactions to the reading experience. They have been edited for grammar and spelling, but not content. 
Table 3.

Selected Quotations

\begin{tabular}{|c|c|}
\hline Student & Snippets \\
\hline 7 & $\begin{array}{l}\text { "I have had some bad experiences with math teachers and how they approach the subject." } \\
\text { "This book has changed my perspective for the better toward math taught in the class and has opened } \\
\text { me to the possibility of taking my math education further in terms of calculus 3." }\end{array}$ \\
\hline 11 & $\begin{array}{l}\text { "[Math] is an important tool in and out of the field of geology... I wish it was something that came } \\
\text { more naturally to me." } \\
\text { "The book didn't change my views on math much. It did change my view on how math should be } \\
\text { taught in lower grade levels." }\end{array}$ \\
\hline 15 & $\begin{array}{l}\text { "My first attempt at calculus } 2 \text { is the stuff of nightmares." } \\
\text { "Going back to basics to understand why we learn the way we do and how we think helps me to } \\
\text { perform better." }\end{array}$ \\
\hline 17 & $\begin{array}{l}\text { "I have learned that there are two different types of math, which I never considered before. There is } \\
\text { abstract math, which is the math we learn in school and fail on calculus tests, and then there is natural } \\
\text { math, which is the innate math skills we are born with." } \\
\text { "Both are just as important as the other, and this book helped me realize that mathematics is a blissful } \\
\text { combination of both." }\end{array}$ \\
\hline 18 & $\begin{array}{l}\text { "I always enjoyed math when the teacher was fun to listen to and explained the concepts in detail and } \\
\text { didn't rush through it because there was a deadline to meet by the end of the year for a test of some } \\
\text { sort. During those years in which the teacher was seemingly "going through the paces" I did not enjoy } \\
\text { the class and I also noticed that my grade would suffer as well because I would find myself bored and } \\
\text { uninterested." } \\
\text { "Seeing how practically everything in the world is using math or math related shows just how important } \\
\text { a subject that it is." }\end{array}$ \\
\hline 19 & $\begin{array}{l}\text { "There is no way I'm going to be able to walk past a tree anymore without stopping to examine a } \\
\text { branch to see if the leaves have a divergence that includes Fibonacci numbers." } \\
\text { "This book makes me want to become a math teacher. (...) I want math to have meaning for everyone." }\end{array}$ \\
\hline 23 & $\begin{array}{l}\text { "Mathematics...has... been quite difficult for me. The problem is... a lack of understanding of why I } \\
\text { was performing such calculations." } \\
\text { "Everything changed for me when I first took a course in statistics. The problems suddenly had } \\
\text { meaning and real world applications." } \\
\text { "This book was the answer to so many questions I have had throughout my academic career beginning } \\
\text { in the } 9^{\text {th }} \text { grade." } \\
\text { "It truly changes the way you look at math problems and has actually helped me in other classes } \\
\text { throughout this semester." }\end{array}$ \\
\hline 24 & $\begin{array}{l}\text { "I only perceived math as a tedious and necessary requirement for a program." } \\
\text { "I do not think my perception of mathematics has changed significantly from reading this book as most } \\
\text { of my personal success in the subject has been with effort and resolve. However, I better understand } \\
\text { why abstract math is incredibly difficult to grasp and retain." }\end{array}$ \\
\hline 27 & $\begin{array}{l}\text { "I still enjoy [math], and quite often wonder what other mathematics haven't even been discovered yet } \\
\text { that will revolutionize our way of thinking." } \\
\text { "[The Math Instinct] was very thought-provoking for me, and I have definitely learned something about } \\
\text { myself in [reading and responding to it]." }\end{array}$ \\
\hline 28 & $\begin{array}{l}\text { "Most math classes, such as algebra and geometry, tend to just use math in a manner where the only } \\
\text { outcome is just another number, without much reason to find that number other than it being a correct } \\
\text { answer. Classes such as these, even though I have done well in them, take a lot more self-motivation } \\
\text { and less enjoyment than those (chemistry) where using the math is part of the enjoyment. But that all } \\
\text { changed once I reached the calculus level of mathematics. Calculus, to me, is a puzzle." } \\
\text { "Overall, what Keith Devlin's The Math Instinct has allowed me to do is think about not just math, but } \\
\text { everything in my surroundings in a different manner." }\end{array}$ \\
\hline
\end{tabular}

Even in a small set of examples, comments coalesce around themes. For example, while the phrase "math anxiety" was not directly mentioned by any of the students, the phrase "test anxiety" was mentioned by Students 24 and 16 in reference to 
chapter 10. ${ }^{3}$ Student 24 stated, "While confidence may play a factor in how well you perform when doing arithmetic, other factors, such as temperament, view towards mathematics, and test anxiety affect performance as well." Meanwhile, Student 16 said,

If you ask someone a simple question in a casual conversation, they won't feel the pressure to be right. Of course, in a casual conversation, you would also tend to estimate rather than doing a precise calculation. However, in a testing situation comes test anxiety. You tend to second guess yourself in test situations and overthink the problem. I think that a lot of people fail to master mathematics in school because of the way the problems are presented to them.

Then, in the final, summative assignment, Student 16 said,

The one critique of the book I have is in regards to chapter 10, which primarily focuses on "street mathematics." Maybe it is because the researchers weren't psychologists (or students recently), but it seemed painfully apparent to me why the vendors and shoppers didn't do as well with the abstract math. Anxiety surrounding tests is extremely common. Though these vendors and shoppers weren't under the pressure of these grades actually being recorded and potentially impacting their lives, I know that I still would have had test anxiety in their situation. Nobody wants to appear unintelligent, so on a test they will most likely second guess themselves and overthink the problem to try to get the best score possible. I talked about this chapter with a few classmates as well, and they were also surprised that Devlin didn't really mention this factor.

Another common theme in the student responses was having a positive attitude or set of experiences regarding math until some pivotal experience changed them. Student 25 described a situation where the student did extremely well in mathematics courses in junior high and high school until taking an AP Calculus, which was taught by a new teacher, and "it was the worst experience I've ever had in a classroom." This student did well in pre-calculus at USF, but struggled in calculus 1 (passing with a B), before failing calculus 2 more than once. Similar statements were noted from Students 2, 3, 6, 7, 10, 11, 13, 19, 20, 22, and 27.

Student 8 finished the assignment by saying, "I did not believe it when they [presumably LV and VR] said that this book is not like other math books, but now I do." This sentiment was also relatively common through other student statements. Student 23, for example, said, "I dreaded cracking the pages of this paperback due to the preconception of boredom waiting in my future," but Student 23 later came to say, "After reading all the chapters I found that this assignment was not menial or boring, it was actually enlightening and probably one of the best reads of my college career." Several students mentioned having an intention to re-read the book

\footnotetext{
${ }^{3}$ Chapter 10 of The Math Instinct discusses street vendors in South America who are able to perform seemingly amazing feats of mental calculation as part of their daily lives, but who, when placed in a testing environment, have difficulty scoring well on math problems such as one would see in school.
} 
later, with Student 27 saying, "it will be placed on my bookshelf to gather dust until I'm ready to read it again."

Several students discussed whether the way students are educated in math should change. Student 13 said, "Maybe our education system should rethink its structure of standardized tests and abstract math to better prepare students for real world problems they will encounter." Student 3 connected the way math is taught to why word problems are "dreaded." Student 7 described liking math but having a "general dislike for how it was taught." Student 10 actually expressed a desire to become a math teacher after reading the book to help change lives for the better.

Some students projected their positive experience with the book to the course itself. Student 16 said, "This book has changed my outlook on the subject, and the course has changed my experience with mathematics (for the better)." Student 25 said, "Having read The Math Instinct, I feel more open and confident when approaching math as a subject in school. The computational geology course has pushed me out of my comfort zone all semester in regards to mathematical concepts and solving word problems."

\section{Discussion and Conclusion}

As noted in the literature, math anxiety - and for that matter, any other affective attitude about math - can come from experiences in school due to how math is presented (Norwood 1994). This connection was noted in several students' comments about where, when, why, and how they stopped having a positive attitude about math. (Although none of the students used the words "math anxiety," it seemed clear that that is what they were describing.) Several students in this study discussed having past negative experiences specifically with math courses. This finding is consistent with anecdotal data from past class cohorts and with interviews with alumni of the course (Ricchezza 2016).

To say that our assignment was successful in the pedagogical sense would be an understatement. Looking forward, an assignment such as this one is all but certain to be included in the fall 2017 semester syllabus (the book chosen ${ }^{4}$ and the details may change, but the essence of the assignment will not). The question for us is not whether we will include such an assignment, but merely what the details will be. One student, for example, would have preferred a choice of books to read rather than simply being told which one was required.

It would be dishonest to suggest that the notion of tackling the affective domain in math (or its subset, math anxiety) was on our minds when we assigned this work. When the reading and writing assignment was constructed and given to students, the major purpose behind it was to improve certain potentially deficient aspects of

\footnotetext{
${ }^{4}$ Actually suggestions are welcome. Please contact the first author.
} 
their QL - that is, to make students more comfortable reading and writing about mathematics. So we also need to admit our good fortune in selecting The Math Instinct as the reading material for the semester book. The tone and style of the book reads like a National Public Radio story. In this regard it is worth noting that Keith Devlin is, indeed, "The Math Guy" on NPR's Weekend Edition, and he is experienced at making his audience feel that, with a bit of explanation of what math is, and a good bit of practice, any of them could be math wizards.

The combination of the reading/writing assignment with the significant amount of contextualized mathematical practice that students get in the CG course appears in this case to have been at least somewhat successful at reducing math anxiety for the students involved. Taken more broadly, the emotional attitude the students showed after reading the book was improved for most students. While the post hoc nature of the study, the single course term/cohort, and the limited nature of the study prevent us from generalizing this study to any broader population, we strongly believe - and we know we are not alone in our belief - that QL-in-discipline courses are an important method for improving student success in QL (Madison 2001), and we think that assignments such as the one we used may be helpful to instructors and students of such courses.

If a formal follow-up study were to be conducted, such a study would include:

- Informed consent (all students would complete the assignment for class credit, but student work would not be used in the study without permission).

- Questions and writing prompts altered to specifically encourage discussion of emotional reactions to math instruction and the assigned text.

- A follow-up survey (not counted for class credit), most likely mixed-methods (quantitative and qualitative), giving students an opportunity to discuss responses openly, anonymously, and without fear of reprisal. (This should also mitigate to some degree the confirmation bias of students telling us what they think we want to hear).

- A determination - to quote an anonymous reviewer - "whether any "popular mathematics exposition book' would yield similar results." (Note: this question could easily lead to a different paper entirely.)

We encourage any readers so inclined to consider further studies of affect change brought about by side reading of mathematical popular nonfiction while taking a hard-core math - or contextualized math - class, as questions raised by our observation in CG merit exploration.

\section{Limitations}

As with any primarily qualitative study, this one has limitations. The assignment set was not designed for a study, but to improve students' abilities to read and write about math concepts. Were a study to be designed from scratch, it would certainly be done differently.

All statements are based on the students' own words. Not only must we take them at their word, we must assume they are being fully expressive, despite 
minimal prompting. That is to say that one student saying 8 of 13 chapters were "interesting" may simply be that student's style of writing, while another student not saying so explicitly is assumed here to mean that that student did not find the book interesting (when this may not be true). A study designed to elicit attitudes about math or a book response would need to be more explicit in asking respondents about items, whether through a survey or through interviews. It should also be noted that in interviews, follow-up questions can be asked; in this case, we are reviewing educational records and cannot ask students for clarification. We must also acknowledge the possibility of confirmation bias in students submitting what they think we want them to say.

Many of the codes and classifications are somewhat arbitrary in the sense that what one person might consider a mixed attitude, another may consider mostly positive. Likewise, not every person clearly stated a change in attitude at the end of the readings/course, and this code had to be inferred from what they said. Making such a determination from a records review rather than surveys or interviews introduces an additional level of uncertainty.

This post hoc study is not intended to be generalizable to any broad population.

\section{Acknowledgment}

We wish to thank the three thoughtful reviewers who helped refine this note for publication. We'd also like to thank the 28 students in the fall cohort of CG, without whose excellent writing responses this note would not have been considered.

\section{References}

Ashcraft, Mark H. 2002. "Math Anxiety: Personal, Educational, and Cognitive Consequences." Current Directions in Psychological Science 11(5): 181-85. Accessed May 23, 2017. https://doi.org/10.1111/1467-8721.00196.

Betz, Nancy E. 1978. "Prevalence, Distribution, and Correlates of Math Anxiety in College Students." Journal of Counseling Psychology 25(5): 441-48. Accessed May 23, 2017. https://doi.org/10.1037/0022-0167.25.5.441.

Devlin, Keith. 2005. The Math Instinct: Why You're a Mathematical Genius (Along with Lobsters, Birds, Cats, and Dogs). New York: Thunder's Mouth Press.

Follette, Katherine, Sanlyn Buxner, Erin Dokter, Donald McCarthy, Beau Vezino, Laci Brock, and Edward Prather. 2017. "The Quantitative Reasoning for College Science (QuaRCS) Assessment 2: Demographic, Academic and Attitudinal Variables as Predictors of Quantitative Ability." Numeracy 10(1): Article 5. Accessed May 23, 2017. https://doi.org/10.5038/1936-4660.10.1.5. 
Furner, Joseph M., and Barbara T. Berman. 2003. "Review of Research: Math Anxiety: Overcoming a Major Obstacle to the Improvement of Student Math Performance." Childhood Education 79(3): 170-74. Accessed May 23, 2017. https://doi.org/10.1080/00094056.2003.10522220.

Glaser, Barney G., and Anselm L. Strauss. 1967. The Discovery of Grounded Theory: Strategies of Qualitative Research. Hawthorne, NY: Aldine Publishing Company.

Hart, Laurie E. 1989. "Describing the Affective Domain: Saying what we Mean." In Affect and Mathematical Problem Solving, edited by Douglas B. McLeod and Verna M. Adams, 37-45. New York: Springer.

Henrich, Allison, and Kristi Lee. 2011. "Reducing Math Anxiety: Findings from Incorporating Service Learning into a Quantitative Reasoning Course at Seattle University." Numeracy 4(2): Article 9. Accessed May 23, 2017. https://doi.org/10.5038/1936-4660.4.2.9.

Ho, Hsiu-Zu, Deniz Senturk, Amy G. Lam, Jules M. Zimmer, Sehee Hong, Yukari Okamoto, Sou-Yung Chiu, Yasuo Nakazawa, and Chang-Pei Wang. 2000. "The Affective and Cognitive Dimensions of Math Anxiety: A CrossNational Study." Journal for Research in Mathematics Education 31(3): 362-79. Accessed May 23, 2017. https://doi.org/10.2307/749811.

Karaali, Gizem, Edwin H Villafane Hernandez, and Jeremy A Taylor. 2016. "What's in a Name? A Critical Review of Definitions of Quantitative Literacy, Numeracy, and Quantitative Reasoning." Numeracy 9(1): Article 2. Accessed May 23, 2017. https://doi.org/10.5038/1936-4660.9.1.2.

Krathwohl, David R., Benjamin S. Bloom, and Bertram B. Masia. 1964. Taxonomy of Educational Objectives, Handbook II: Affective Domain. New York: David McKay Company, Inc.

Latiolais, M. Paul, and Wendi Laurence. 2009. "Engaging Math-Avoidant College Students." Numeracy 2(2): Article 5. Accessed May 23, 2017. https://doi.org/10.5038/1936-4660.2.2.5.

Lipka, Orly, and Itay Hess. 2016. "Attitudes Toward Statistics Studies among Students with Learning Disabilities." Numeracy 9(2): Article 7. Accessed May 23, 2017. https://doi.org/10.5038/1936-4660.9.2.7.

Madison, Bernard L. 2001. “Quantitative literacy: Everybody's Orphan.” MAA Focus 21(6): 10-11.

- 2006. "Pedagogical Challenges of Quantitative Literacy." Proceedings of the Joint Statistical Meetings.

- 2014. "How Does One Design or Evaluate a Course in Quantitative Reasoning?" Numeracy 7(2): Article 3. Accessed June 1, 2017. https://doi.org/10.5038/1936-4660.7.2.3.

Maloney, Erin A., and Sian L. Beilock. 2012. "Math Anxiety: Who Has It, Why It Develops, and How to Guard Against It." Trends in Cognitive Sciences 16 
(8): 404-6. Accessed May 23, 2017.

https://doi.org/10.1016/j.tics.2012.06.008.

Mayfield, Betty, and Jill B. Dunham. 2015. "Adapting to a New Core Curriculum at Hood College: From Computation to Quantitative Literacy." Numeracy 8(2): Article 8. Accessed May 23, 2017. https://doi.org/10.5038/1936$\underline{4660.8 .2 .8 .}$.

Norwood, Karen S. 1994. "The Effect of Instructional Approach on Mathematics Anxiety and Achievement." School Science and Mathematics 94(5): 248-54.

Accessed May 23, 2017. https://doi.org/10.1111/j.1949-8594.1994.tb15665.x. Ricchezza, Victor J. 2016. "Alumni Narratives on Computational Geology (Spring 1997-Fall 2013).” Graduate Theses and Dissertations. M.S. Thesis, University of South Florida. Accessed May 23, 2017.

https://scholarcommons.usf.edu/etd/6366.

— Geology,' an Evolving, In-Discipline Course in Quantitative Literacy at the University of South Florida." Numeracy 10(1): Article 6. Accessed May 23, 2017. https://doi.org/10.5038/1936-4660.10.1.6.

Steen, Lynn Arthur. 1999a. "Twenty Questions about Mathematical Reasoning." In Developing Mathematical Reasoning in Grades $K-12$, edited by Lee Stiff, 270-85. Reston, VA: National Council of Teachers of Mathematics.

_. 1999b. "Numeracy: The New Literacy for a Data-Drenched Society." Educational Leadership 57: 8-13. Accessed May 23, 2017. http://www.ascd.org/publications/educational_leadership/oct99/vol57/num02 Numeracy@_The_New_Literacy_for_a_Data-Drenched_Society.aspx.

- 2000. "Reading, Writing, and Numeracy." Liberal Education 86(2): 2637. Accessed May 23, 2017. Available at https://pdfs.semanticscholar.org/8511/9262fd98b70c3a0fdba2f915f93d890e7 d96.pdf.

Sundre, Donna, Carol Barry, Vidar Gynnild, and Erin Tangen Ostgard. 2012. "Motivation for Achievement and Attitudes Toward Mathematics Instruction in a Required Calculus Course at the Norwegian University of Science and Technology." Numeracy 5(1): Article 4. Accessed May 23, 2017. https://doi.org/10.5038/1936-4660.5.1.4.

Vacher, H.L. 2000. "A Course in Geological-Mathematical Problem Solving." Journal of Geoscience Education 48(4): 478-81. Accessed May 23, 2017. https://doi.org/10.5408/1089-9995-48.4.478. . 2006. "Role of Geoscience Education in Promoting Quantitatve Literacy." Presentation in Infusing Quantitative Literacy into Introductory Geoscience Courses, June 26-28, Carleton College, Northfield MN. 
. 2014. "Looking at the multiple meanings of numeracy, quantitative literacy, and quantitative reasoning." Numeracy 7 (2): Article 1. Accessed May 25, 2017. https://doi.org/10.5038/1936-4660.7.2.1.

— , and Emily Lardner. 2010. "Spreadsheets Across the Curriculum, 1: The Idea and the Resource." Numeracy 3(2): Article 6. Accessed May 23, 2017. https://doi.org/10.5038/1936-4660.3.2.6.

Wang, Xueli. 2013. "Why Students Choose STEM Majors." American Educational Research Journal 50(5): 1081-121. Accessed May 23, 2017. https://doi.org/10.3102/0002831213488622.

Wismath, Shelly L, and D Bruce Mackay. 2012. "Quantitative Courses in a Liberal Education Program: A Case Study." The Journal of General Education 61(4): 314-22. Accessed May 23, 2017. https://doi.org/10.5325/jgeneeduc.61.4.0314.

Wismath, Shelly L, and Alyson Worrall. 2015. "Improving University Students' Perception of Mathematics and Mathematics Ability." Numeracy 8(1): Article 9. Accessed May 23, 2017. Accessed May 23, 2017. https://doi.org/10.5038/1936-4660.8.1.9. 